\title{
La integració en aules AICLE: quan les mestres creuen fronteres
}

\author{
Catalina Cladera Artigues \\ CEIP Nadal Campaner Arrom
}

Laura Valdés-Sánchez

Universitat Autònoma de Barcelona

(Text rebut el 05 de setembre de 2017; acceptat el 23 de març de 2018)

DOI: http://doi.org/10.5565/rev/jtl3.741

Resum: El procés de globalització de les últimes dècades ha fomentat la valoració de l'aprenentatge de llengües estrangeres. En el context europeu, la llengua anglesa esdevé un objectiu prioritari en els sistemes educatius, que han anat introduint diferents programes bilingües. Un d'ells és l'AICLE (Aprenentatge Integrat de Continguts i Llengua Estrangera), en el que s'ensenya una matèria no lingüística en llengua anglesa o en una altra llengua estrangera. Aquest enfocament a dies d'avui es presenta com un gran repte pel professorat degut a la seva manca de formació. En aquest article s'analitza la interacció entre els alumnes i dues mestres que ensenyen l'anglès i les ciències conjuntament (cada una especialista en un camp) en una aula d'educació primària. Es pretén comprendre com es fa aquesta integració analitzant el focus d'atenció de les mestres i quin paper hi juguen els usos de les distintes llengües.

Paraules clau: AICLE, coteaching, integració, plurilingüisme, primària

\begin{abstract}
The process of globalization over the last decades has fostered the appreciation of the learning of foreign languages. In the European context, the learning of English as a second language becomes a priority in the educational systems, which have introduced several bilingual programs. Among these programs, we highlight CLIL (Content and Language Integrated Learning), which consists of the teaching of a non-language subject in English or another foreign language. This approach is often a challenge for teachers due to the lack of teacher education in this field. In this article some classroom interaction sequences are analyzed. Two primary school teachers (each one is a specialist in a different subject) interact with pupils while teaching Science in English. We aim to comprehend how this integration of content and language is carried out by analyzing the teachers' focus and the role that plurilingualism plays.
\end{abstract}

Keywords: CLIL, coteaching, integration, plurilingualism, primary school

Resumen: El proceso de globalización de las últimas décadas ha fomentado la valoración del aprendizaje de lenguas estranjeras. En el contexto europeo, el aprendizaje de la lengua inglesa es un objetivo prioritario en los sistemas educativos, que han introducido varios programas biligües. Entre éstos, destacamos el CLIL (Content and language integrated learning), que consiste en la enseñanza de una materia no lingüística en lengua inglesa. Este enfoque se presenta como un reto para el profesorado debido a la falta de formación. En este artículo se analiza la interacción en 
una aula de primaria entre alumnos y dos maestras que enseñan inglés y ciencias conjuntamente (cada maestra es especialista en una área). Se pretende comprender cómo se lleva a cabo esta integración analizando el foco de atención de las maestras y el papel que desempeñan los usos de las distintas lenguas.

Palabras clave: AICLE, coteaching, integración, plurilingüismo, primaria

\section{Introducció}

Molts països de la Unió Europea promouen nous plans educatius bilingües que integren l'ensenyament d'una llengua estrangera amb l'ensenyament d'altres àrees no lingüístiques. Aquest és l'enfocament que es coneix amb l'abreviació CLIL (Content and Language Integrated Learning) o AICLE (Aprenentatge integrat de continguts i llengua estrangera) en català. En aquest context, a la comunitat de Catalunya trobem molts projectes de centre que aposten per una integració de l'aprenentatge de les ciències i l'anglès. La raó per la qual s'impulsen aquests projectes és la percepció de l'AICLE com un avantatge per a l'aprenentatge de la llengua estrangera alhora que suposa també un benefici per a l'aprenentatge del contingut (Gajo, 2007). A més, es parteix de la idea que una llengua estrangera s'aprèn en una situació contextualitzada al voltant dels continguts curriculars d'una àrea no lingüística. Ara bé, la majoria de centres escolars s'enfronten a una gran dificultat, i és disposar de professorat que sigui competent en les dues especialitats: l'anglès i les ciències. I és que el problema prové des de la formació inicial del professorat, que rarament preveu una orientació bivalent entre llengua i disciplina denominada no lingüística (DdNL) i les seves necessitats específiques (Gajo, 2011).

Una de les primeres iniciatives en aquest sentit es va iniciar en el curs 2012-2013 a la Universitat Autònoma de Barcelona (UAB), que va començar a oferir el Grau d'Educació Primària en anglès (GEPa), on s'imparteixen actualment un $60 \%$ de les assignatures en llengua anglesa. Tot i que les avaluacions realitzades al programa GEPa demostren que l'alumnat millora la seva capacitat per a la internacionalització, doncs millora la seva competència discursiva en llengua estrangera sens perjudici del seu rendiment acadèmic o en la llengua primera (Arnau Sabatés, Borràs-Comes i Escobar Urmeneta, 2018; Borràs-Comes i Escobar Urmeneta, 2018), no es refereixen al GEPa com un grau especialitzat en la formació de professorat d'AICLE. En el marc de la formació no inicial en AICLE a l'estat espanyol, hi ha dues monografies que documenten programes de formació lingüística i metodològica per a professorat AICLE que coordina la Conselleria d'Educació de cada comunitat autònoma: CLIL in Spain: Implementation, results and teacher training (Lasagabaster \& Ruiz de Zarobe, 
2010) i CLIL across education levels levels: Opportunities for all (Dafouz \& Guerrini, 2009).

La implementació de l'AICLE requereix un treball cooperatiu entre especialistes que pugui assegurar una vertadera integració de la llengua i el contingut sense rebaixar la qualitat de l'ensenyament de les diferents àrees. L'exemple que s'analitza en aquest article esdevé un tipus de model de col·laboració entre el professorat AICLE. En aquest model dues mestres d'educació primària de diferents especialitats comparteixen la docència dins una mateixa aula i s'aprecia com ambdues docents es responsabilitzen de l'ensenyament i aprenentatge de les dues àrees, i no només d'aquella en la que són especialistes.

\section{Pregunta i objectius d'investigació}

En aquest article es pretén analitzar i comprendre com dues mestres (una especialista en la llengua meta i l'altra en ciències) interaccionen entre elles i els alumnes per arribar a integrar l'ensenyament de la llengua estrangera amb l'ensenyament de continguts no lingüístics. Llavors ens preguntem: a) Com gestionen les dues especialistes els continguts de llengua i els continguts de ciències en la interacció amb els alumnes?; b) Quin paper juga l'ús del plurilingüisme en aquesta aula que parteix d'un currículum trilingüe? Per això, es farà una anàlisi de fragments de cinc episodis discursius que considerem representatius per la rica interacció de les dues mestres i dels alumnes. Els episodis són d'una aula de tercer de primària mentre es fa una part de l'àrea de coneixement del medi social i natural en anglès: Science.

\section{L'enfocament AICLE}

El procés de globalització de les últimes dècades ha conduït a una major consideració del valor social, cultural i econòmic de conèixer llengües estrangeres. Seidlhofer remarca que "Tot $\mathrm{i}$ ser benvinguda per alguns i desaprovada per altres, no es pot negar que l'anglès funciona com una lingua franca global" (Seidlhofer 2015, p. 339). Per això, s'ha anat integrant progressivament en els sistemes educatius europeus i cada vegada esdevé un objectiu d'ensenyament i aprenentatge més important. En aquest context, moltes comunitats autònomes han començat a desenvolupar projectes bilingües per impulsar l'aprenentatge de llengües estrangeres. Entre aquests programes, destaquem la iniciativa del Consell d'Europa per crear polítiques lingüístiques basades en el plurilingüisme des d'un enfocament interdisciplinari: 1'AICLE. Així, un dels primers textos que reflecteix la cooperació europea en matèria de l'AICLE és la Resolució del Consell de 1995 (Eurydice, 2006). 
D'acord amb Eurydice (2006), el terme CLIL (Content and Language Integrated Learning) s'empra per definir qualsevol situació d'ensenyament-aprenentatge en la que una segona llengua és emprada per ensenyar una disciplina diferent de les disciplines lingüístiques, promovent un ensenyament bilingüe. El que ens sembla interessant en aquest article és comprendre aquesta integració.

\section{El coteaching a les aules AICLE}

Algunes recerques han demostrat que el coteaching és un context avantatjós per millorar l'aprenentatge de l'alumne i també per aprendre a ensenyar (Roth i Tobin, 2004). Aquest terme de coteaching, o docència compartida, el definim com una pràctica de "dos o més professors [...] que planifiquen, instrueixen i avaluen conjuntament [...], un procés i no pas un resultat final” (Davis-Willey i Crespo, 1998). Així, alguns dels beneficis són: que els aprenents reben més atenció individualitzada i perceben que algú sempre està dispost a ajudar-los; els alumnes poden observar diferents perspectives, veure com els professionals negocien i col-laboren mútuament; i es promou un ambient més participatiu i una atmosfera més oberta per a la interacció (Davis-Willey i Crespo, 1998).

Els contextos AICLE presenten nous reptes pels docents, que Valdés-Sánchez i Espinet (2013) identifiquen com: la falta de materials adaptats; la possibilitat d'oferir una exposició a L2 adequada; la tensió que existeix entre l'ensenyament de la llengua i l'ensenyament de la disciplina; i la manca de formació específica. Front aquests reptes, exposen algunes aportacions de la docència compartida que la seva recerca ha permès identificar: la planificació de forma conjunta de materials per part d'experts en llengua i ciència permet l'elaboració d'aquests nous materials adaptats a situacions AICLE; el fet que hi hagi a l'aula un expert en L2 en tot moment pot assegurar l'exposició adequada a la llengua meta; la planificació col·laborativa per part d'especialistes en ciències i anglès assegura que hi hagi una preocupació pels objectius de les dues àrees; i l'aprenentatge recíproc, l'augment de la capacitat de maniobra, l'autocrítica, la reflexió i les discussions constructives milloren la formació d'ambdós docents.

A més a més, també ha estat documentada la influència positiva que el coteaching té sobre la formació del professorat (Valdés-Sánchez i Espinet, 2013; Roth i Tobin, 2004). Roth i Tobin (2004) introdueixen el concepte de l'espai de maniobra (room to maneuver) com un conjunt de recursos disponibles i possibilitats d'actuar de cada mestre per afrontar les 
situacions del dia a dia; i descriuen com aquest espai de maniobra de dues mestres va canviant durant una experiència de coteaching.

\section{El concepte d'integració}

Davison and Williams (2001) analitzen la integració de la llengua i el contingut en el context de la recerca en programes d'aprenentatge de l'anglès com a segona llengua (ESL; English as a Second Language). Proposen diferents perspectives d'integració organitzades en forma de gradació que depenen del focus d'atenció per part del professorat en l'ensenyament de la llengua o del contingut. Per descriure aquesta gradació tenen en compte el focus del currículum, el model teòric o l'enfocament emprat, els materials d'ensenyament, els tipus d'agrupacions d'aula, i els rols dels mestres o models de col·laboració més comuns. La proposta pretén oferir un marc de referència per a l'anàlisi de l'ensenyament, els materials d'ensenyament, la naturalesa dels currículums i altres elements en el context d'ESL a diferents nivells curriculars (nivell d'activitat, unitat, seqüència didàctica, pla d'estudis, programa...). En l'article ens centrarem en el nivell d'activitat i exemplificarem les diferents gradacions en el discurs de les mestres. La gradació va des de una major atenció a la llengua fins a un major èmfasi en els continguts:

- Ensenyament de la llengua: es treballa la llengua fora de context des de un enfocament pre-comunicatiu. El contingut no influeix i el/la mestre/a especialista de llengua és el/la que programa i imparteix les classes.

- Ensenyament contextualitzat de la llengua: les activitats de llengua estan contextualitzades, per la qual cosa s'empra un enfocament comunicatiu, tot i que és dèbil (centrat en la forma de la llengua). L'especialista de llengua es troba al capdavant de l'ensenyament però pot comptar amb l'ajuda de l'especialista en contingut en alguns moments.

- L'ensenyament integrat de llengua i contingut. Es defineixen objectius comuns entre les dues àrees. Els enfocaments basats en la teoria de gèneres (genre-based approaches) són els més utilitzats. Se sol treballar conjuntament: mestre/a especialista en contingut i mestre/a especialista en llengua.

- L'ensenyament del contingut conscient de la llengua (o sheltered instruction). Es treballa el contingut $\mathrm{i}$ alhora s'adopten una sèrie de bastides (scaffoldings) per ajudar a desenvolupar el llenguatge. El/la mestre/a de suport lingüístic ajuda al/la mestre/a especialista en el contingut. 
- L'ensenyament del contingut (o immersió): s'ensenya el contingut en L2 sense parar atenció en 1'ensenyament-aprenentatge d'aquesta segona llengua. El model emprat és el que coneixem com a immersió. El/la mestre/a és l'especialista en contingut.

Per a Gajo (2007) la integració entre llengua i contingut es dóna en el procés interactiu i discursiu d'ambdues disciplines. Així, el lèxic i les estructures discursives que utilitzen alumnes i mestres impliquen un coneixement tant del llenguatge com del contingut que s'ensenya. Per comprendre com es fa la integració dels continguts lingüístics i no lingüístics en una aula AICLE cal estudiar què passa en una aula quan es realitzen aquests programes. Gajo (2011) exposa la necessitat de pressuposar una sèrie de qüestions per poder plantejar i descriure aquesta integració. En primer lloc, no és possible separar el llenguatge (oral o escrit) de l'aprenentatge escolar, independentment de la disciplina que es tracti, i per això ell parla de DdNL (Disciplina denominada no lingüística). A més, planteja la necessitat de contextualitzar les tasques comunicatives en l'escola; i, finalment, comprendre que el plurilingüisme és una eina natural d'accés al coneixement.

D'acord amb Gajo (2011), per poder afrontar les tasques de la disciplina no lingüística, caldrà emprar les eines lingüístiques. Així, el discurs pot presentar-se opac quan hi ha un menor domini de les eines lingüístiques en L2 o dens quan hi ha obstacles en la conceptualització dels continguts de la disciplina. L'opacitat del contingut o la densitat del discurs requereixen l'atenció dels participants i comporten processos de re-mediació dels sabers (quan l'aprenent s'enfronta a un obstacle lingüístic degut a l'opacitat del discurs que llavors resoldrà o aclarirà) fins que s'arriba a la saturació (entesa com un punt de sortida de la negociació situada del significat). Així, com més opac és el discurs, més informació es necessitarà del paradigma lingüístic, i com més dens, més informació provindrà del paradigma disciplinar (Gajo, 2007).

Barwell (2005) creu que l'atenció (la focalització en certs aspectes de la interacció precedent i del context) i la seqüencialitat (que descriu l'estructura de la interacció) són conceptes clau a l'hora d'entendre la integració. Els contextos AICLE suposen parar una doble atenció: per una banda, als continguts que s'han de saber; i per l'altra, als recursos lingüístics en L2 per dir allò que es vol dir (Moore \& Nussbaum, 2011). En aquests processos, jugaran un paper clau les hetero- i autoreparacions (mecanismes pels quals els parlants tracten el que perceben com un obstacle a l'hora de construir un significat, ja sigui en el discurs dels demés o en el propi, respectivament). 


\section{EI rol del plurilingüisme a les aules AICLE}

D'acord amb Moore i Nussbaum (2011), nombroses investigacions destaquen que els participants d'una activitat situada en aules plurilingües són capaços de desplegar els seus repertoris plurilingües per poder afrontar tasques en L2. Aquests recursos actuarien de bastida per poder participar en les dites tasques. Una de les capacitats dels parlants plurilingües és la de poder alternar codis lingüístics distints o crear noves formes lingüístiques híbrides innovadores. És el que es coneix com a codeswitching o alternança de codis.

Però encara que aquesta funció del plurilingüisme és rellevant quan apareix a nivell local (codeswitching), les alternances apareixen a diferents nivells de l'organització social del discurs (Gajo et al., 2013). Així, podem distingir tres nivells: micro, meso i macro (Gajo et al., 2013). En aquesta investigació ens referirem al nivell micro quan hi ha alternança espontània de codis en el discurs; meso, quan estem parlant a nivell de planificació didàctica; i macro, quan ens referim al nivell curricular.

En una aula AICLE l'alternança a nivell micro compleix diverses funcions, com negociar el significat, interpretar el context de la conversa o la preferència d'ús d'una llengua. D’acord amb Moore i Nussbaum (2011), els recursos plurilingües són elements clau en les activitats de re-mediació dels sabers i en la saturació del contingut.

\section{Enfocament metodològic en l'anàlisi de dades}

Per poder interpretar les dades, adoptem una perspectiva socio-cultural de l'aprenentatge i l'ensenyament, doncs considerem que és a través de la interacció entre els participants que es construeix l'aprenentatge. Així, les normes i els valors d'aquesta interacció són negociats pels mestres i alumnes, que co-construeixen el discurs. Ens inspirem en les aportacions de l'Anàlisis Conversacional (AC) per analitzar les dades interaccionals de l'aula. Aquest enfocament ens permetrà descriure com les mestres actuen per promoure l'aprenentatge de l'alumnat, ja que l'AC ofereix eines útils per analitzar l'activitat de les persones i com aquestes interactuen per orientar-se cap a l'ensenyament i/o l'aprenentatge (Moore i Nussbaum, 2011).

De l'AC, ens servirem dels conceptes de presa de la paraula, parells adjacents, seqüencialitat, preferència i reparació per analitzar les nostres dades (Sacks, 1992; Moore i Nussbaum, 2011). La presa de paraula, els parells adjacents i la seqüencialitat ens serviran per definir l'estructura de la parla (els diferents torns i les seqüències de parla que giren entorn una determinada tasca). La prefèrencia permet comprendre quins comportaments 
prioritaris demostren les mestres. Finalment, la reparació és el tractament d'un problema que sorgeix en la interacció i que és un obstacle per a la comunicació. Considerem la reparació com un procediment clau en una interacció on un dels objectius és l'aprenentatge de la llengua estrangera (L2). A més, estem d'acord amb Barwell (2005) en tant que l'atenció (també extret de l'AC) és un concepte clau per entendre la integració entre les dues disciplines (anglès i ciències). Per això analitzarem el focus d'atenció de les mestres i també l'atenció que requereixen les distintes tasques per part dels alumnes.

Per acabar, l'ús de l'AC ens permetrà observar el conjunt de recursos que els parlants utilitzen en una aula AICLE, com els recursos plurilingües i multimodals que intervenen en el procés d'ensenyament-aprenentatge d'una segona llengua (Moore i Nussbaum, 2011).

\section{Context per a l'obtenció de dades}

Les dades ${ }^{i}$ utilitzades en aquest estudi van ser recollides per comprendre els rols de participació de dues mestres en el context de coteaching, i analitzar les interaccions de llengua i contingut. Van ser preses a una aula de tercer de primària d'una escola pública de Sant Cugat del Vallès. Les mestres ja havien treballat juntes per engegar un projecte de AICLE a l'escola: Science. El projecte pretén fer ciència des de la indagació integrant la llengua anglesa (llengua meta). De les quatre hores setmanals de coneixement del medi, una és de Science. Les dues mestres havien participat en el projecte de recerca en AICLE anomenat DALE-APECS (Academic Discourse in a Foreign Language: Learning and Assessment of Science Content in the Multilungual CLIL Classroom) en el que hi participaren investigadors en didàctica de les ciències i les llengües de la Universitat Autònoma de Barcelona i mestres de primària. Una de les mestres, que és la tutora del grup, té molta experiència en l'ensenyament de les ciències basat en la indagació. L'altra mestra és l'especialista d'anglès del centre. En un principi, està acordat que la mestra d'anglès parli l'anglès (L2) i la mestra de ciències en català (L1). Les mestres planifiquen les sessions i defineixen els objectius conjuntament.

\section{Anàlisi de dades}

En aquest article analitzem diversos fragments interactius o vinyetes. Ens fixem en com l'ensenyament del contingut i de la llengua estan integrats (si ho estan) a partir de quin és l'objectiu i el focus d'atenció de les mestres en cada un dels fragments, segons la gradació de 
Davison i Williams (2001). Aquests elements es poden identificar en el discurs, i per això s'ha realitzat una transcripció àmplia (broad).

Els fragments transcrits $\mathrm{i}$ analitzats formen part de tres episodis o moments interactius diferents que van tenir lloc durant la segona sessió d'una tasca que consistia en la construcció de tovots (maons de fang i palla). Aquesta activitat forma part del projecte "Houses through History" que les mestres fan a Science, i té la finalitat de construir un tovot com ho feien a la prehistòria. En aquesta segona sessió, els alumnes recorden quins materials, eines i accions necessiten per fer el tovot i planifiquen la recollida dels materials a la classe (Episodis 1, 3, 5 i 6). Després surten a fora a recollir els materials i finalment organitzen els grups i el treball per la següent sessió (Episodi 20).

A totes les vinyetes analitzades participen la Mc (mestra de ciències), Ma (mestra d'anglès) $\mathrm{i}$ els alumnes (Ax, quan no distingim un alumne en concret i $\mathrm{A}_{1,2,3 \ldots}$ quan sí ho fem). A més, en una vinyeta hi és present una Mv (mestra visitant) que no interactua en aquest episodi que analitzem, però és una auxiliar de conversa de l'escola. Totes les converses tenen lloc a l'aula de tercer de primària. Els alumnes estan asseguts en grups de 4 i les dues mestres no ocupen un espai determinat, sinó que es van movent per l'aula.

Tot seguit presentem i analitzem diverses vinyetes que exemplifiquen cadascun dels graus d'integració definits per Davison i Williams (2001): ensenyament de la llengua, ensenyament contextualitzat de la llengua, ensenyament simultani integrat de la llengua i continguts, ensenyament de continguts conscient de la llengua, i ensenyament del contingut.

Ensenyament de la llengua. En aquest primer fragment (Figura/Vinyeta 1), els alumnes i les dues mestres estan revisant uns murals amb fotografies que han preparat els alumnes amb el procés de fer els tovots. Llavors la Ma va llegint i corregint el peu de les imatges que els alumnes han escrit (torn 4). La Ma demana qui fa totes aquestes accions, s'ajuda dels gestos (assenyala amb el dit) per identificar el subjecte de les oracions en anglès i passa a centrar-se en la part escrita de la llengua (lletrejar el pronom personal " $W e$ " en anglès).

Veiem, doncs, com la mestra d'anglès s'allunya del contingut de ciències per treballar un aspecte purament de gramàtica. La Ma repeteix les oracions introduint el pronom (torn 6) i la Mc intervé demanant en català si vol que ho escrigui a la pissarra i demanant als alumnes que l'ajudin. Ma torna a intervenir de nou per demandar que els alumnes responguin en llengua anglesa, doncs la Mc havia alternat el codi i havia fet la demanda en català, per la qual cosa els alumnes podrien haver contestat en català si la Ma no hagués demostrat la seva preferència de codi. 
Aquest és un exemple d'ensenyament de la llengua, doncs encara que la tasca (fer els murals) té un objectiu integrat de llengua i contingut científic, veiem com la mestra focalitza l'atenció en un aspecte lingüístic i deixa totalment de banda el contingut disciplinar.

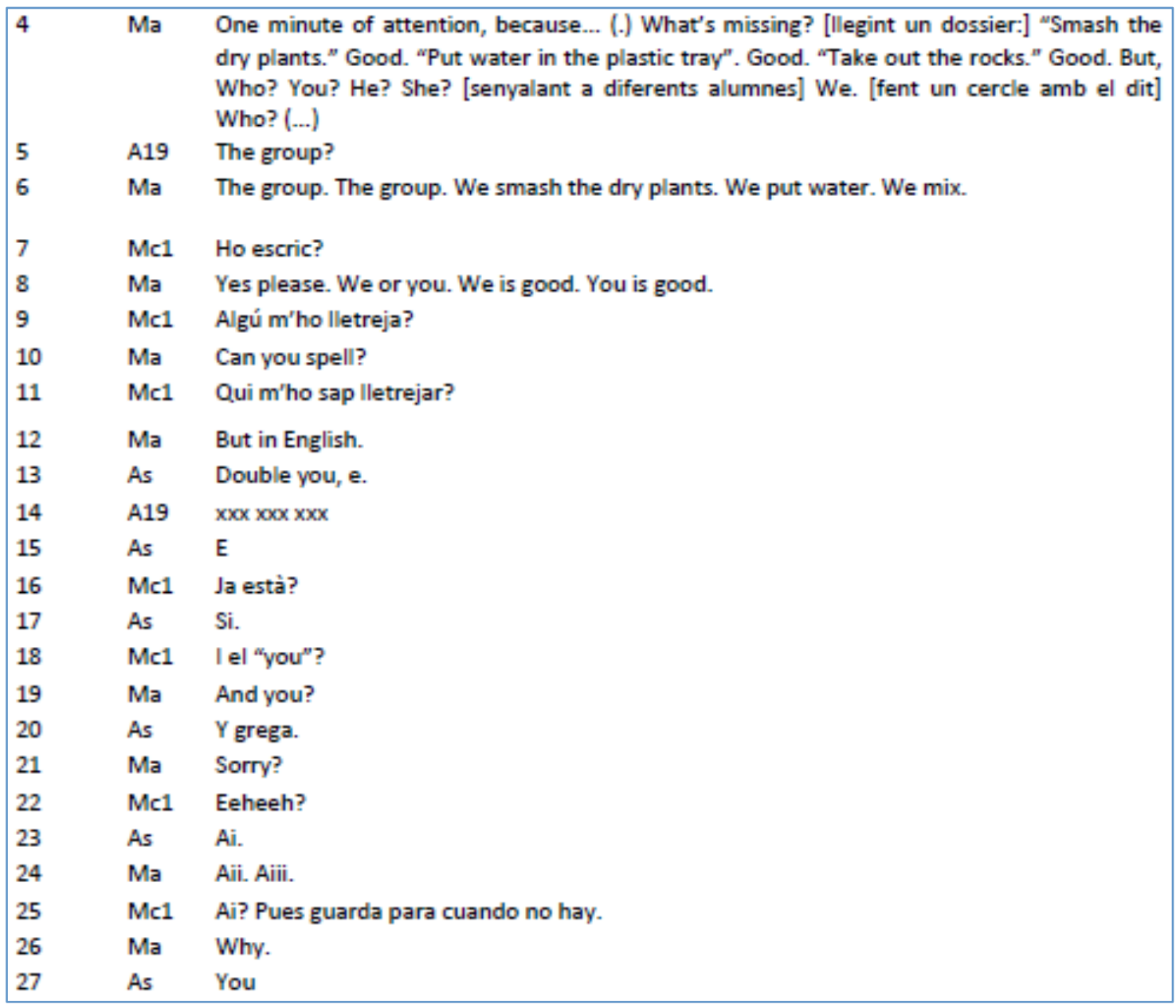

Vinyeta 1. Exemple d'Ensenyament de la llengua (Episodi 3: Hem de posar pronoms, com s'escriuen?)

Ensenyament contextualitzat de la llengua. A la Vinyeta 2, la Ma (mestra d'anglès) pregunta què podran construir amb els tovots que facin. La Mc és la que introdueix la paraula nova " $h u t$ ", i l'experta utilitza els gestos per representar la paraula (torn 60). Després la Ma demana el significat de la paraula $i$ els alumnes entren en l'opacitat del discurs, que mitjançant un procés de re-mediació acabarà amb la saturació en el torn 87: la traducció de la paraula en català. Aquesta traducció al català (alternança de codi) en aquest cas ha permès superar l'opacitat del discurs.

En aquesta seqüència veiem com hi ha un canvi d'objectiu: des de focalitzar en el contingut (la funció tecnològica dels tovots) a parar l'atenció en la llengua (el significat de la 
paraula "hut"). Les dues mestres participen amb el mateix objectiu i co-construeixen el discurs.

En aquest cas veiem clarament un ensenyament de la llengua contextualitzat, ja que quan es parlava de la funció tecnològica dels tovots s'ha requerit prestar atenció al contingut lingüístic. En el torn 91 veiem com la Mc desvia l'atenció altre cop cap el contingut disciplinar, ja que demana si en la pre-història s'empraven els tovots per construir cabanes i inicien una discussió del tema que es duu a terme en L1. En aquesta nova seqüència (que en aquest fragment es troba tallada per falta d'espai) es fa evident un ensenyament focalitzat tan sols en el contingut. No podem dir, doncs, que hi hagi hagut una integració de llengua i contingut. Però sí que podem dir que les ciències han actuat de context i que la llengua s'ha ensenyat, així, de forma contextualitzada: la nova paraula "hut" no s'ha introduït de forma forçada, sinó per necessitat del context. 


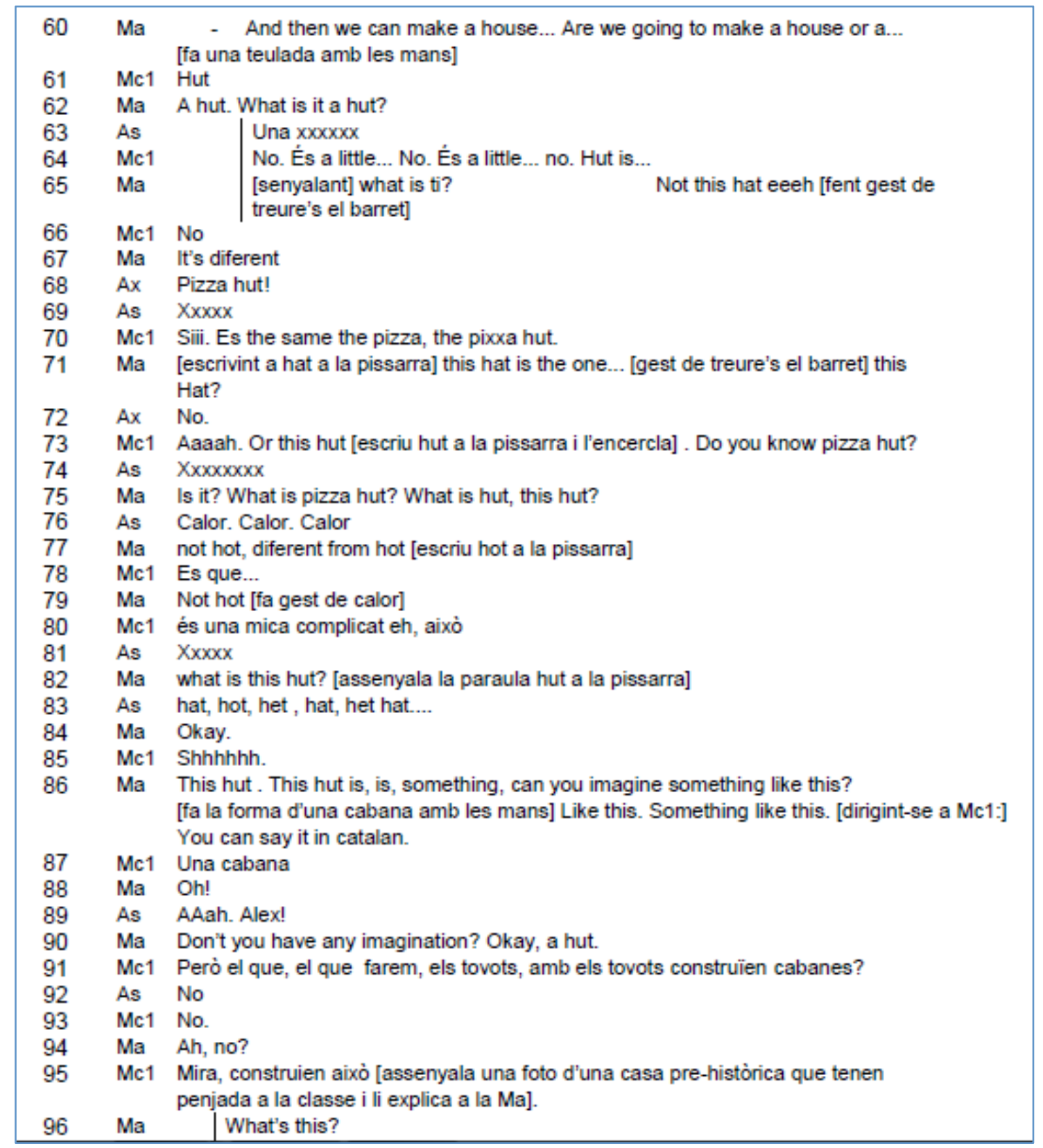

Vinyeta 2. Episodi 20: Què podem construir amb els tovots?

Ensenyament simultani integrat de llengua $i$ continguts. En aquest fragment s'inicia una nova seqüència quan la Mc demana quins materials aniran a cercar per poder construir els tovots. Mc pronuncia "materials" en anglès i Ma reformula tota la pregunta en anglès. Mc ha alternat el codi perquè pretén que els alumnes diguin els materials en L2; així l'alternança ha indicat quina era la seva preferència. Llavors els alumnes responen en anglès, doncs han captat aquesta preferència. Els estudiants tot plegats (no es poden distingir diferents torns perquè no aixequen la mà) responen amb els noms dels materials però enlloc de pronunciar “weeds" algun d'ells ha dit "witch", el que provoca rialles i una hetero-reparació per part de 
Ma que, finalment, en el torn 85 , acaba amb una repetició de la paraula correcta per part dels alumnes.

En aquest cas, es requereix una doble atenció per part dels alumnes: per una part, és necessari que pensin en tots els materials que formen un tovot; per altra banda, han de pensar com dir cada un dels materials en L2 (clay, weed, straw, water). Per tant, en aquest fragment podem afirmar que hi ha hagut una integració entre els sabers lingüístics i els sabers disciplinaris. D’acord amb la gradació de Davison i Williams (2001), veiem un cas d'ensenyament simultani integrat de llengua i continguts.

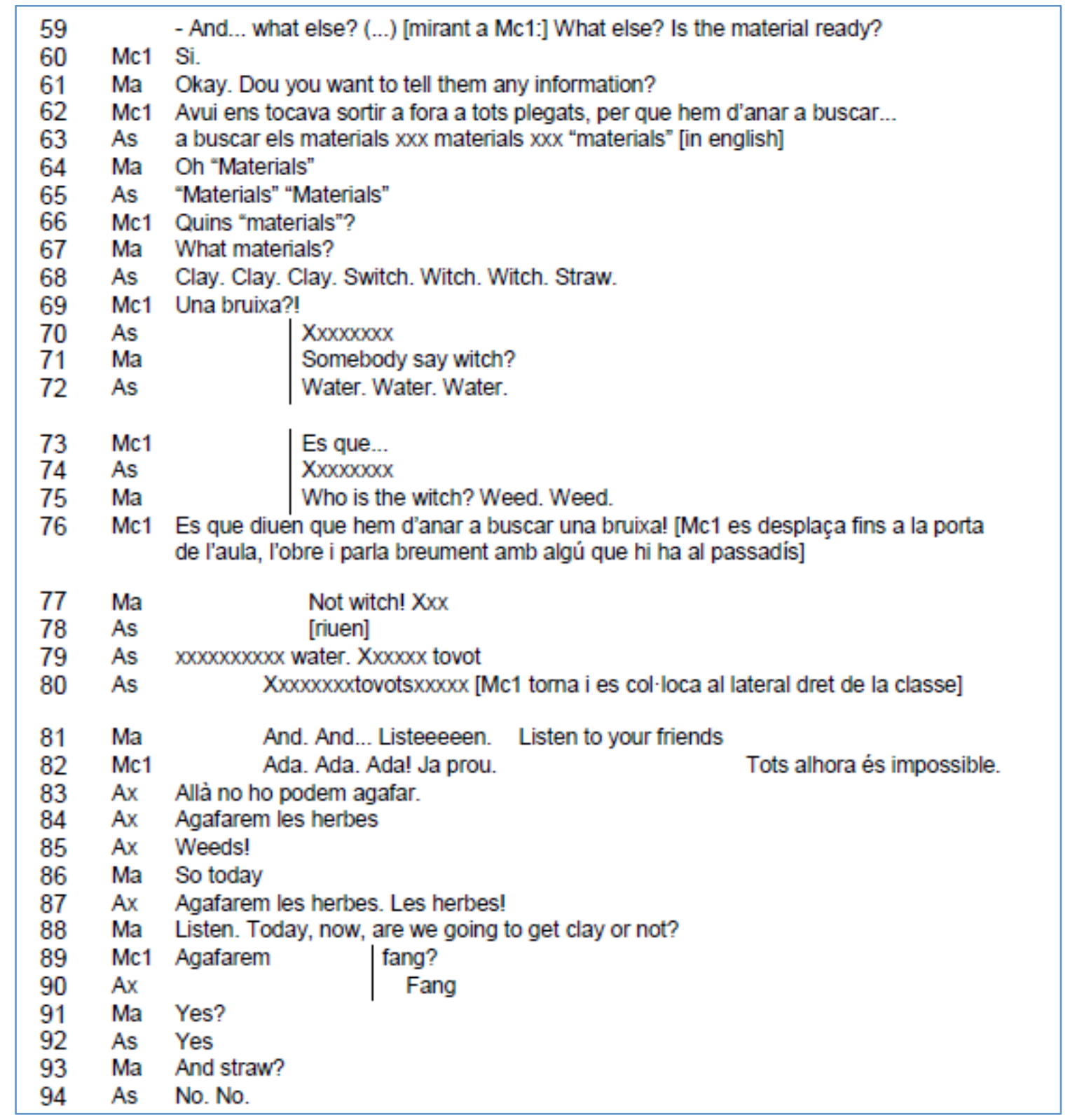

Vinyeta 3. Episodi 1: Quins materials anem a buscar? 
Ensenyament del contingut conscient de la llengua. En aquest espisodi estàn explicant a l'auxiliar de conversa de l'escola el que necessiten per fer un tovot. Els nois i noies diuen "weeds" i la mestra d'anglès introdueix un contingut nou, i és que no serveix qualsevol tipus d'herba, sinó que ha de ser herba seca. Per tant, “dry weeds". L'atenció de la mestra d'anglès, doncs, està focalitzada en el contingut, encara que introdueix el contingut en la llengua meta. Per això, aquest seria un exemple de l'estadi que proposen Davison i Williams (2001): l'ensenyament del contingut conscient de la llengua.

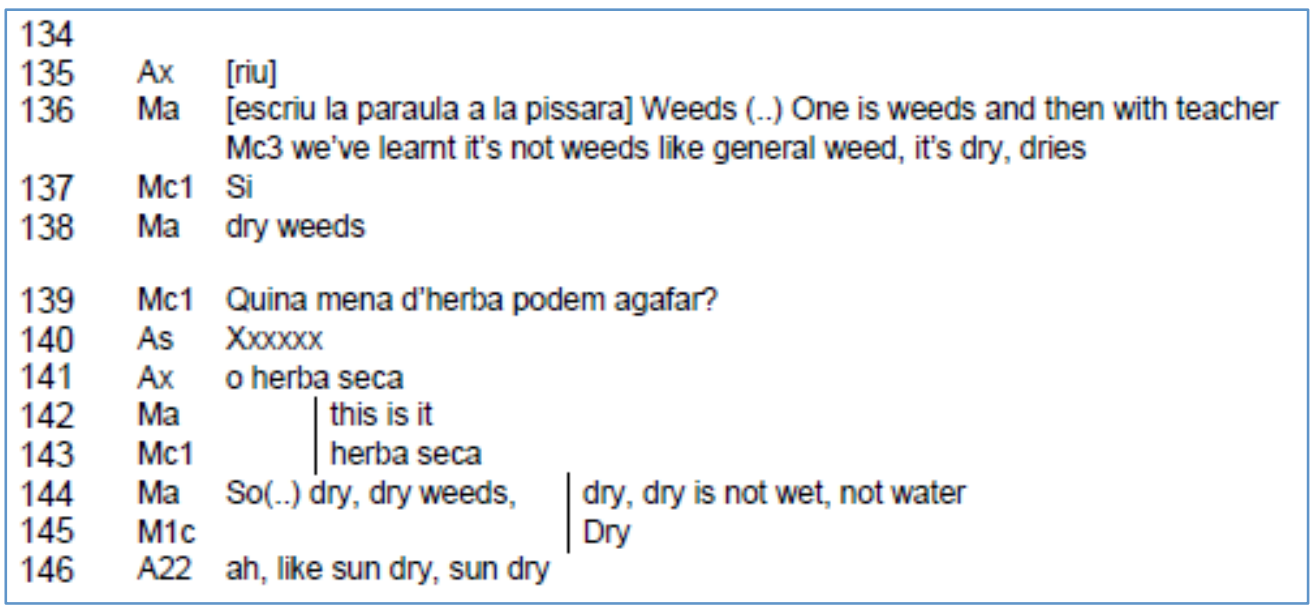

Vinyeta 4. Episodi 5: Quina mena d'herba podem agafar?

Ensenyament del contingut. La Vinyeta 5 correspon amb un fragment que és la continuació del fragment anterior (Vinyeta 4). En aquest moment, la densitat del contingut porta a les dues mestres a centrar l'atenció en el paradigma disciplinar, ja que han de fer una distinció entre herba seca, herba humida i herba mullada. Llavors, encara que Ma és la que presenta el nou contingut en el fragment anterior, es manté al marge mentre Mc condueix la discussió per diferenciar el tres tipus d'herba. En tot moment ho fa en L1 i els alumnes també contesten en L1. Per això, exemplifiquem l'esenyament del contingut amb aquest fragment, en el que no es para atenció a L2. 


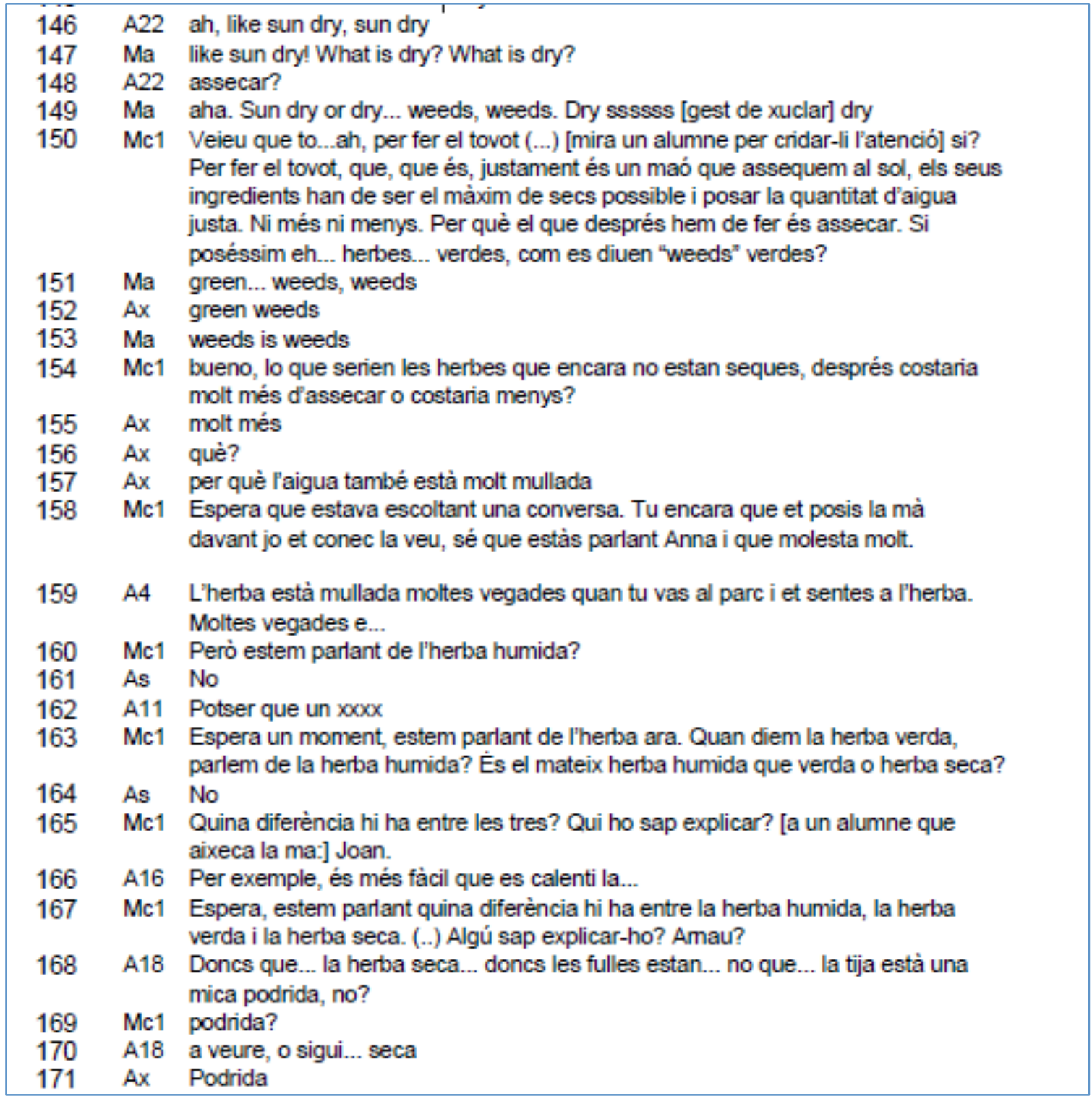

Vinyeta 5. Episodi 6: Aclarim la diferència entre herba seca, herba humida i herba mullada.

\section{Discussió}

Després d'analitzar aquests fragments on constantment interaccionen les dues mestres i els alumnes, podem concloure que el fet de que hi hagi dues mestres especialistes no significa que existeixin barreres en l'espai de maniobra -en termes de Roth i Tobin (2009)- de cada mestra, contràriament a allò que es podria pensar en una situació de docència compartida en aules AICLE. Tant els objectius lingüístics com els objectius de contingut de ciències són comuns en les dues mestres, que molt sovint amplien aquest espai de maniobra i adopten una responsabilitat totalment compartida. Així, encara que a nivell meso estigui pactat que la mestra d'anglès parli L2 i la de ciències L1, la mestra de ciències a nivell micro utilitza moltes alternances de codi per reforçar el vocabulari en anglès o per mostrar la seva 
preferència perquè els nens i nenes responguin en la llengua meta. De la mateixa manera, la mestra d'anglès, com hem vist amb l'exemple més clar a la Vinyeta 3, agafa el rol de mestra de ciències en el moment que focalitza l'interès en un aspecte purament de contingut de ciències. Per tant, en els tres moments que hem exemplificat d'ensenyament contextualitzat de la llengua, ensenyament integrat de llengua i contingut, i ensenyament de contingut conscient de la llengua hi identifiquem objectius comuns d'ambdues mestres. Ara bé, també creiem convenient insistir en què aquestes dues mestres ja havien treballat juntes altres cursos i per això el seu espai de maniobra s'ha anat ampliant, d'acord amb la recerca de Valdés-Sánchez i Espinet (2012).

També resulta interessant l'ús que es fa de la L1 en aquesta aula AICLE. El fet de que la mestra de ciències parli la L1 afavoreix l'aparició dels modes plurilingües de comunicació o plurilanguaging (Lüdi, 2011). La L1 no està prohibida, sinó que s'empra com a bastida quan els nens i nenes elaboren el discurs en anglès. A més, serveix per rebaixar l'opacitat del discurs i per arribar a la saturació del contingut (Vinyeta 1). També creiem que aquest és un aspecte que incrementa la motivació dels alumnes, doncs observen com la mestra de ciències, que no és experta en L2, empra tot el seu repertori per emprar la llengua meta. La mestra d'anglès ho accepta i molts cops reformula el que ha dit la mestra de ciències. La mestra d'anglès, de la mateixa manera, a cops es presenta com inexperta en el contingut i demostra que ella també està aprenent (ho podem veure al final de la Vinyeta 1).

\section{Implicacions}

L'enfocament AICLE es presenta com una pràctica en expansió que suposa un repte al professorat, que es veu en la difícil situació de dominar l'ensenyament de dues disciplines i en la necessitat de trobar la manera d'integrar aquests dos ensenyaments. Aquest article presenta una experiència en la que la col·laboració entre dues mestres, una especialista en anglès i una especialista en ciències, ofereix un context favorable per a la construcció d'un projecte d'integració de l'ensenyament de les ciències i de l'anglès que es preocupi per la qualitat en l'ensenyament d'ambdues disciplines.

L'anàlisi de la interacció d'aquestes dues mestres, amb experiència en la col·laboració docent i en la integració de les ciències i la llengua, mostra dos aspectes importants que cal considerar a l'hora de dur a terme un projecte AICLE.

D'una banda, existeixen diversos nivells d'integració de la llengua i del contingut, i en un context d'ensenyament caldrà fer ús de tots ells depenent de les exigències del moment. 
L'atenció es mourà entre un ensenyament o l'altre en funció de la necessitat d'afrontar la densitat conceptual o l'opacitat lingüística del discurs. De l'altra, les alternances lingüístiques tenen un paper important en el context AICLE, tant en l'ensenyament de la llengua com en l'ensenyament del contingut.

\section{Referències}

Arnau Sabatés, L., Borràs-Comes, J., i Escobar Urmeneta, C. (2018). Rendimiento académico y estudios universitarios con docencia en inglés (DUI): el caso del grado en Educación Primaria de la UAB. A C. Escobar Urmeneta i L. Arnau Sabatés (Eds.), Los retos de la internacionalización de los grados universitarios en el contexto del Espacio europeo de Educación Superior (pp. 135-146). Madrid: Síntesis.

Barwell, R. (2005). Integrating language and content: Issues from the mathematicsclassroom. Linguistics and Education, 16: 205-218. DOI: http://doi.org/10.1016/j.linged.2006.01.002

Borràs-Comes, J., i Escobar Urmeneta, C. (2018). El desarrollo de la competencia discursiva en lengua extranjera en un entorno ICLES: la efectividad de la estrategia GUIDEWAY. A C.Escobar Urmeneta i L. Arnau Sabatés (Eds.), Los retos de la internacionalización de los grados universitarios en el contexto del Espacio europeo de Educación Superior (pp. 115-134). Madrid: Síntesis.

Dafouz, E. \& Guerrini, M. (Eds.) (2009). CLIL across education levels: opportunities for all. Madrid: Richmond-Santillana Publishing.

Davison, C., i Williams, A. (2001). Integrating language and content: Unresolved issues. A B. Mohan, C. Leung i C. Davison (Eds.), English as a second language in the mainstream (pp. 51-70). Harlow, UK: Pearson Education Ltd.

Davis-Willey, P., i Crespo, A. (1998). Are two instructors better than one?: Planning, teaching and evaluating à deux. Annual Meeting of the Mid-south Educational Research Association. New Orleans, Louisiana.

Eurydice (2006). Content and Language Integrated Learning (CLIL) at school in Europe. Brussels: Eurodyce European Unit. Disponible a http://eacea.ec.europa.eu/ressources/eurodyce/p df/0integral/071EN.pdf

Gajo, L. (2007). Linguistic knowledge and subject knowledge: How does bilingualism contribute to subject development? The International Journal of Bilingual Education and Bilingualism, 10(5): 563-581. DOI: https://doi.org/10.2167/beb460.0 
Gajo, L. (2011). Trabajar en otra llengua para elaborar saberes en uns disciplina. A C. Escobar, i L. Nussbaum (Eds.), Aprendre en una altra llengua/Learning through another Language/Aprender en otra llengua (pp. 53-70). Bellaterra: Servei de Publicacions de la UAB.

Gajo, L., A. Grobet, C. Serra, G. Steffen, G. Müller I A. C. Berthoud (2013). Plurilingualisms and knowledge construction in higher education. A A.-C. Berthoud, F. Grin, i G. Lüdi (Eds.), Exploring the dynamics of multilingualism: The DYLAN project (pp. 287-308). Amsterdam: John Benjamins. DOI: http://doi.org/10.1075/mdm.2.13gaj

Labajos, D., i Martin, L. (2011). Content integration in bilingual education: educational and interactional practices in the context of MEC-British Council partneship in Madrid Region. A Escobar, C., N. Evnitskaya, E. Moore, i A. Patiño (Eds.), AICLE CLIL - EMILE. Educació plurilingüe: Experiencias, research \& polítiques. Bellaterra: Servei de Publicacions de la UAB.

Lasagabaster, D., i Ruiz de Zarobe, Y. (Eds.) (2010). CLIL in Spain: Implementation, results and teacher training. Newcastle: Cambridge Scholars Library.

Lüdi, G. (2011). Vers de nouvelles approches théoriques du langage et du plurilingüisme. Travaux neuchâtelois de linguistique, 53, 47-64.

Moliner, M. (2013). The effects of CLIL from perspective of in-service teachers in Salamanca (Castilla y León, Spain). Revista Científica Exedra, 8, 200-217.

Moore, E. i Nussbaum, L. (2011) Què aporta l'anàlisi conversacional a la comprensió de les situacions d'AICLE. A C. Escobar, i L. Nussbaum, L. (Eds.) Aprendre en una altra llengua / Learning through another language / Aprender en otra llengua (pp. 93 118). Bellaterra: Servei de publicacions de la UAB.

Roth, W. M., i Tobin, K. G. (2004). Coteaching: From praxis to theory. Teachers and Teaching: Theory and Practice, 10(2), 161-180. DOI: http://doi.org/10.1080/1354060042000188017

Sacks, H. (1992). Lectures on conversation. Oxford: Blackwell

Seidlhofer, B. (2005). Key concepts in ELT. English as a lingua franca. ELT Journal, 59(4), 339-341.

Valdés-Sánchez, L. i Espinet, M. (2012). Construint l'aprenentatge integrat de ciències i anglès a Primària. Retrat d'una evolució fruit del coteaching i la pràctica autoreflexiva (treball de fi de màster inèdit). Bellaterra: Universitat Autònoma de Barcelona. 
Valdés-Sánchez, L. i Espinet, M. (2013). Ensenyar ciències i anglès a través de la docència compartida. Ciències. Revista del Professorat de Ciències, d'Infantil, Primària $i$ Secundària, 25, 26-34.

\section{Annex}

\section{Pautes de transcripció}

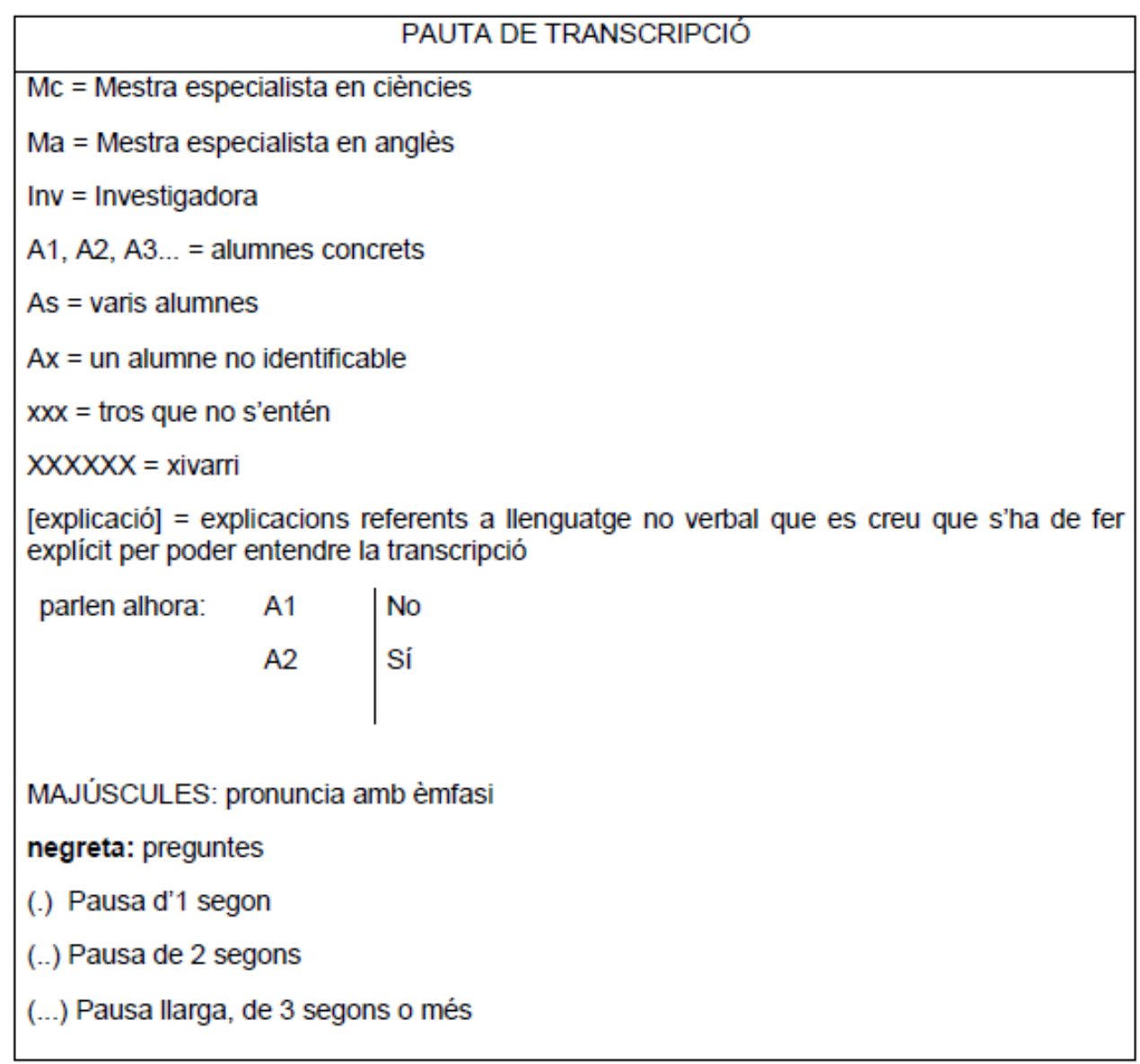

\footnotetext{
${ }^{i}$ Les dades pertanyen al corpus de LIEC (http://grupsderecerca.uab.cat/liec/). Van ser enregistrades i transcrites per L. Valdés-Sánchez. Vegeu a l'annex els símbols emprats en les transcripcions.
} 


\section{Informació sobre les autores:}

Catalina Cladera Artigues és mestra en actiu d'educació primària a les Illes Balears. La seva àrea de recerca és la integració del contingut i el llenguatge a l'educació primària. En aquesta línia, la seva tesi de màster en Recerca en Educació va anar dirigida a identificar les dificultats dels mestres de primària a l'hora de crear materials que integressin les ciències i la llengua anglesa.

Email: cata.cladera@gmail.com

Laura Valdés-Sánchez, graduada en Biologia per la Universitat de Barcelona, és professora associada de la Universitat Autònoma de Barcelona. Va defensar la seva tesi de doctorat al 2016, a la Universitat Autònoma de Barcelona. La seva recerca es centra en l'ús del llenguatge per a l'ensenyament-aprenentatge de les ciències experimentals; els contexts d'aprenentatge integrat de ciències i llengua; i els processos de col·laboració entre docents com a eina de millora de la pràctica i de desenvolupament professional.

Email: lauravaldessanchez@gmail.com

Per citar aquest article:

Cladera Artigues, C. i Valdés-Sánchez, L. (2018). La integració en aules AICLE: quan les mestres creuen fronteres. Bellaterra Journal of Teaching \& Learning Language \& Literature, 11(1), 43-62. DOI: http://doi.org/10.5565/rev/jt13.741 